\title{
Development of the mammary gland
}

\author{
C. H. Knight and M. Peaker \\ Department of Physiology, The Hannah Research Institute, Ayr KA6 5HL, U.K.
}

\section{Introduction}

The first obvious statement is that the mammary gland is an intriguing structure, and that its development is one of the most fascinating aspects. During the lifetime of the animal the mammary gland probably undergoes more and greater changes in size, structure, composition and activity than any other tissue or organ. These changes start during fetal life and continue even after the gland has reached maturity since it waxes and wanes during successive reproductive cycles. In its most advanced state, that of full lactation, the gland possesses vast numbers of specialized secretory cells (parenchyma) together with supporting connective and adipose tissue (stroma); it may produce considerably more than its own weight of secretion every day or, in energetic terms, as many joules per day as it contains in its own mass.

The second obvious statement is that the actual yield of milk is a function of the amount produced by each secretory cell (which must be subject to a fixed maximum, but as yet unknown, value) and the number of secretory cells. Hence those factors which determine the epithelial cell population are crucial to the control of milk production.

The control of mammary growth is a complex process involving factors intrinsic to the gland (local control) or the whole animal (systemic control) as well as external influences such as environment, climate and diet. Furthermore, it now appears that the gland has an important controlling role in its own right since it has considerable influence on reproductive processes in at least one species. Thus although mammary development has been studied for many years (and the hormonal requirements for mammary development form a classic of endocrinology) there is undoubtedly much left to discover, in qualitative as well as quantitative terms.

In this article, we shall first describe the pattern of development of the gland, then discuss the control of development, and finally consider the gland as a controller rather than as the controlled.

\section{Pattern of development}

\section{Measurement of mammary development}

A number of techniques are available for the study of mammary growth. Depending on the species and the stage of glandular development, one, all or none of these methods may be applicable (see Munford, 1964).

Measurement of gross size (volume) of large glands may be achieved simply by water displacement à la Archimedes (see Linzell, 1966). This technique gives a relatively reliable indication of the functional size of the lactating gland in some species (e.g. goats, dairy cows) but not in others in which there is a high ratio of stroma to parenchyma (e.g. man) or in conditions in which this ratio is high or in animals in which the glands are relatively inaccessible.

Measurement of the gross or defatted weight of glands removed, for example from small laboratory animals, takes no account of the changing composition of the gland, leading to 
problems with the non-lactating gland (particularly with respect to adipose tissue) and the lactating gland, owing to variation in the amount of retained milk.

Morphometric analysis allows the determination of, amongst other variables, the number of secretory cells present. However, a representative sample of the gland must be obtained and even with the aid of computer analysis this method is time-consuming.

A simple method of determining changes in cell number is by measurement of the total tissue content of DNA (DNA $)_{t}$; this should not be confused with DNA concentration ([DNA]) which is not indicative of the size of the cell population. The content of DNA is virtually constant from cell to cell and does not change significantly with different stages of pregnancy, lactation and involution. This method has been widely applied (see Cowie, Forsyth \& Hart, 1980), but it does have one severe limitation in that it determines all cells rather than specifically measuring the lobulo-alveolar or secretory cells. This is not a major problem during pregnancy and lactation when the epithelial cell population is changing dramatically but that of the non-secretory portion is almost static (Paape \& Sinha, 1971).

Periods of intense growth can be identified by measuring the rate of cell proliferation in the gland, although for a complete picture - and for derivation of cell kinetic data - the rate of cell loss should also be determined. Counting of cells in mitosis and the incorporation of $\left[{ }^{3} \mathrm{H}\right]$ thymidine into DNA can both be used to determine proliferation but no entirely satisfactory method exists for the measurement of cell loss.

A severe limitation of all these methods, with the exception of volume measurements, is that they are invasive. In small animals it is common practice to kill animals at appropriate stages but for economic or ethical reasons this approach is often not applicable to large animals. The tendency in such cases is to study each animal at several different times, removing only part of the glandular mass at each stage. This approach presents problems related to the size of sample taken. The larger the sample (e.g. one gland of the two in goats), the more representative it is of the total tissue mass, but the more likely is its removal to affect the growth of the remaining tissue (compensatory growth). The smaller the sample (i.e. biopsies), the less representative it is, but the less likely it is to affect future development.

What is needed of course is a non-invasive technique which could be used in all animals in all reproductive states - one of the pipe-dreams of the mammary physiologist. At least for some species two lines of work may yield promising results for the future. The first is a volume measurement, not of gross size but of internal volume or functional capacity (Peaker, 1980). Changes in this capacity, which is relatively easy to determine in goats, may reflect changes in the total size of the alveolar portion of the gland. However, the most exciting prospect is to be able to identify compounds which are specifically utilized or produced by proliferating cells and others which are unique to dying cells. By measuring the uptake or output of such compounds in vivo (using arterio-venous difference techniques) it would be possible to monitor changes in the rates of cell proliferation and cell loss. The observation that pteridine and its derivatives are excreted by proliferating cells (Wachter, Hausen, Reider \& Schweiger, 1980) may prove to be the first step in opening up this exciting new approach.

Thus while many existing methods are applicable to the study of the mammary cell population in most animals, we know of no methods by which such information can be obtained for man, other than by grossly invasive action or post mortem.

\section{Mammary development before first conception}

In general, little or no true lobulo-alveolar development occurs before first pregnancy. This period is essentially one in which a framework is laid down within which the specialized secretory cells will be able to proliferate. As such it forms a vital part of the gland's overall developmental strategy, and derangements occurring during fetal and juvenile life can seriously reduce the size and secretory potential of the mature gland. 
Comparative studies of mammary development in the fetus have recently been reviewed by Cowie et al. (1980), and the process is not considered in detail here. In mice and rabbits the earliest changes are brought about by morphogenetic movement of cells rather than by proliferation (Balinsky, 1950); this pattern may be common to all species. Three stages of fetal development stand out as crucial determinants of the architecture of the mature glands. Firstly, the length of the mammary line and crest (bilateral ectodermal thickenings) determines the positioning of the glands (i.e. inguinal, abdominal, thoracic). Secondly, the number and precise location of the glands are determined by the number and position of mammary buds (spheres of ectodermal cells sunken into the dermis along the mammary line). Thirdly, the basic structure of the duct system is determined by the number of canalized primary sprouts which develop from the buds and by the number of secondary sprouts which branch off these.

Sexual dimorphism is apparent in fetal mammary development, generally as an inhibition of growth in the male.

While the rudiments of the mammary tissue are developing the first signs of the essential ancillary structures (i.e. blood vessels, nerves, lymphatics, connective tissue and myoepithelial cells) appear. With the exception of myoepithelial cells and nerves these structures all arise from the mesenchymal layer which underlies the mammary epithelium. Another essential differentiative product of the mesenchyme is the adipose tissue which forms the mammary fat pad. Without the fat pad the mammary epithelium cannot proliferate or differentiate, and it provides the necessary space, support and local control for duct elongation and, ultimately, lobulo-alveolar proliferation.

Development of the gland during juvenile life consists of an ordered extension of ducts within the fat pad. This growth is restricted to the fat pads; there is an inhibitory zone around each duct into which other ducts cannot penetrate and in normal circumstances development does not proceed beyond the duct end-bud stage, i.e. lobulo-alveolar tissue is not formed. Extension of the fat pad also occurs, primarily as a result of cell hypertrophy (enlargement) rather than cell hyperplasia (proliferation).

A number of observations suggest that endocrine changes at parturition stimulate mammary growth in the neonate. In man, precocious development and fluid secretion ("witch's milk") is not uncommon in babies (Dossett, 1960). Histological studies reveal extensive duct growth early in life. Korfsmeier (1979) has measured the proliferative activity of neonatal mouse mammary tissue; activity was high on Day 2, then decreased, but rose again from Day 10 to achieve a labelling index of $10 \%$ which was maintained for several weeks. In rats, mammary growth is initially isometric but an allometric phase commences after weaning at Days 21-23; the latter is dependent on intact ovaries although it precedes puberty by several weeks (Cowie, 1949). Measurement of DNA $\mathrm{A}_{\mathrm{t}}$ in heifers also indicates a switch from isometric to allometric growth well in advance of puberty (Sinha \& Tucker, 1969).

Fluctuations in mammary cell proliferation related to the oestrous cycle have been detected in pubertal mice, hamsters and rats, although unfortunately none of these studies included comparative data from prepubertal animals. Release of oestrogens during pro-oestrus stimulates DNA synthesis (Sutton \& Suhrbier, 1967) which is followed by mitosis during late oestrus and metoestrus (Grahame \& Bertalanffy, 1972). Korfsmeier's (1979) labelling index of $10 \%$ in prepubertal mice is very similar to values reported for peak labelling index during the oestrous cycle; it is possible, therefore, that mammary growth is inhibited during the luteal phase of the cycle rather than stimulated during the oestrogenic phase. Measurement of DNA $\mathrm{t}_{t}$ in rats and heifers supports this argument, because growth around oestrus is followed by regression during the luteal phase (Sinha \& Tucker, 1966, 1969). Accordingly, the overall increase in cell number during each cycle is small and is generally only incremental for a few cycles. Furthermore, since the collagen content also increases (Paape \& Sinha, 1971) the ratio of parenchyma to stroma remains low.

Pubertal mammary development in man is rather different, as all will have realized at some 
stage of their development. The size of the breast-a secondary sexual character in this species-increases markedly and often very rapidly (Marshall \& Tanner, 1969) due almost entirely to the deposition of fat. Not only does this process not increase the functional capacity of the breast, but indeed may even impair it because although the mammary epithelium cannot proliferate without a fat pad, too much fat, at least in dairy cows, can be detrimental. Work at the A.R.C. Institute for Research on Animal Diseases has shown that heifers fed on a high plane of nutrition reach puberty earlier and have much larger mammary glands. However, these glands are very fatty, like those of man (a female version of the minotaur?), their content of glandular tissue is reduced and when they subsequently lactate their milk yield is lower than that of animals given less food before puberty (I. W. Reynolds, personal communication).

Some animals which exhibit a different pattern of post-pubertal growth are those which undergo pseudopregnancy. Spontaneous pseudopregnancy, as occurs in the dog, is accompanied by a degree of mammary development similar to that which occurs during pregnancy. Induced pseudopregnancy, as in rabbits, rats and mice, results in development which is terminated rather earlier, probably at the time that implantation would have occurred if the animal were pregnant (see Short \& Drife, 1977).

\section{Mammary development during pregnancy}

It has been estimated that $94 \%$ of all mammary growth takes place during gestation in the hamster (Sinha, Anderson \& Turner, 1970), 78\% in the mouse (Brookreson \& Turner, 1959) and sheep (Anderson, 1975b), 66\% in the rabbit (Lu \& Anderson, 1973) and 60\% in the rat (Griffith \& Turner, 1961). These figures are necessarily approximate; nevertheless they do underline the significance of development during pregnancy, normally referred to as mammogenesis. Before first conception the gland consists of a partly-developed duct system lying in an extensive fat pad (it may well be more developed at the start of subsequent pregnancies, hence this section refers specifically to the primigravid animal). Histological studies have shown that during gestation the duct system increases in size and complexity and epithelial cells proliferate, displacing adipose tissue and forming the first true lobulo-alveolar tissue. Contrary to the belief of early workers proliferation continues throughout the whole of gestation, and sometimes into lactation. For a comparative review of mammogenesis in many species, see Cowie et al. (1980).

Measurements of the percentage increase in both wet weight and defatted dry weight of the six abdominal inguinal glands of rats during pregnancy vary from 50 to $120 \%$, whereas the equivalent figures for $\mathrm{DNA}_{t}$ range from 200 to $300 \%$. Since the latter reflects cell number, and hence the size of the functional portion of the gland, it is obvious that weight determinations alone seriously underestimate the increase in secretory potential. The data of Munford (1963) demonstrated a roughly linear increase of $\log \mathrm{DNA}_{\mathrm{t}}$ with time throughout pregnancy and for the first 5 days of lactation. A similar relationship exists in mice from Day 12 of pregnancy to Day 5 of lactation (Knight \& Peaker, 1982b). It would appear, therefore, that mammary cell number increases in an exponential fashion during gestation in these two species. The mouse has a cell population doubling time of 6 days; in the rat it is somewhat longer. Our own results and those of Traurig (1967a) for the mouse and Grahame \& Bertalanffy (1972) for the rat indicate that the proportion of dividing cells declines during the second half of pregnancy; thus in order to maintain exponential growth the time taken for each cell to divide must decrease, as is known to occur under the influence of ovarian steroids (Bresciani, 1971).

The site(s) of cell proliferation within the growing gland are not known for certain. Bresciani (1971) produced autoradiographs showing that DNA-synthesizing cells were present only in the terminal structures (end buds) of the duct system in virgin mice, whereas during pregnancy cells of the ducts themselves were also capable of division. He was also of the opinion that there were no specific foci of division within individual alveoli, although as far as we are aware this point 
has never been satisfactorily investigated. There is little evidence for the existence of a stem cell population within the mammary gland, although Devore (1977) claims to have identified, in peri-parturient rat tissue, a population of actively dividing primitive cells, which give rise to intermediate cells which may themselves either divide or complete differentiation. Stem cell-derived growth is generally linear rather than exponential, unless the size of the stem cell population is also increasing; thus our results do not support a simple stem-cell concept.

Marked changes occur in the mammary gland towards the end of gestation. In the mouse individual epithelial cell size increases markedly (Foster, 1977) possibly in part as a result of accumulation of secretion. There are considerable differences between species in relation to the stage of gestation at which secretory products are first observed (lactogenesis stage I; Fleet $e t$ al., 1975); because changes in cell size greatly affect DNA concentration it is essential to base growth studies on $\mathrm{DNA}_{t}$, rather than on DNA concentration.

\section{Mammary development during lactation}

It is worth emphasizing once again that milk yield is a function of the number of secreting cells and the activity of each cell. The size of the secretory cell population increases dramatically during gestation, but in some species at least the story does not end there. It is well established that a transient surge of cell proliferation occurs 2 or 3 days post partum in the mouse (Traurig, 1967b; Knight \& Peaker, 1982b) and rat (Richardson, Slater \& Greenbaum, cited in Greenbaum

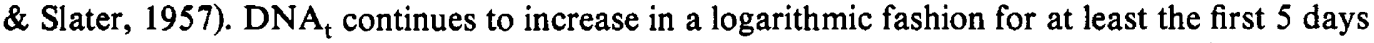
of lactation in these species; our own results for the mouse show that the cell population doubles in size between the last day of pregnancy and the 5th day of lactation. Milk yield increased gradually for the first 7 days of lactation in the same study; part, but not all, of this increase was explained by the proliferation of epithelial cells.

This raises an interesting problem concerning the origin of cell proliferation in lactating tissue. The evidence for a stem cell population is very limited (see above), and it would appear that the cells of any given alveolus differentiate in an all-or-none fashion (i.e. all are differentiated or all are undifferentiated) (Keenan, Saacke \& Patton, 1970), which leaves three possibilities. The first is formation of completely new alveoli from proliferation of end bud cells, which to our knowledge has not been observed. The second is proliferation of undifferentiated cells in those alveoli which are non-secretory, although such alveoli are rare. The third is proliferation of differentiated cells in any alveolus. It was thought that differentiated cells were incapable of division (Mayer \& Klein, 1961), but recent evidence has shown that this may not be so (Franke \& Keenan, 1979).

In the guinea-pig there is relatively little change in $\mathrm{DNA}_{\mathrm{t}}$ during gestation, but there is a large increase within 2 days after parturition (Nelson, Heytler \& Ciaccio, 1962). This may result from a wave of mitosis pre partum rather than from proliferation during lactation. The glands of rabbits apparently increase in size and DNA content late in lactation (Lu \& Anderson, 1973), although studies of $\left[{ }^{3} \mathrm{H}\right]$ thymidine labelling index have failed to detect any increase in cell proliferation at this time.

What happens in the large domestic species? DNA concentration remains relatively unchanged during early lactation in the sheep (Anderson, 1975b), goat (Anderson, Harness, Snead \& Salah, 1981) and cow (Baldwin, 1966), although possible variations in the size of the glands and retained milk content of the tissue mean that this observation alone is not indicative of a lack of growth. In preliminary studies using serial tissue biopsies we have been unable to detect any post-partum mitotic activity in the goat mammary gland, although results obtained so far

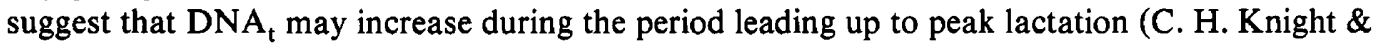
M. Peaker, unpublished). It has previously been assumed that mammary cell number is essentially determined pre partum in the cow, goat and sheep, in which case increase in the secretory activity of individual cells and in the ratio of differentiated to non-differentiated cells must account in total for the rise from early post-partum yield to peak. We do not believe this! 
How does the gland change later in lactation? Having said that increased yield at peak may involve both greater cell activity and a larger cell population, can we also claim that the subsequent decline in yield is caused by a loss of cells coupled with a reduction in cellular activity? Cell loss certainly occurs, and our own results suggest that DNA $_{t}$ may fall concomitantly with yield in mice, although this has still to be confirmed. When lactation is extended in rodents by litter replacement a gradual decline in milk yield is accompanied by a fall

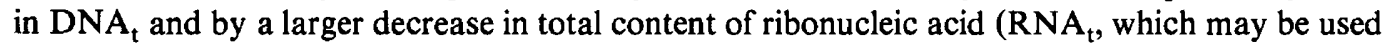
as a measure of functional capability of the tissue), which suggests that decreased secretion is related more to reduced cellular activity than to loss of cells (Nagasawa \& Yanai, 1976).

The normal pattern of events is for the lactation to run its course, after which the gland involutes, or regresses. Cessation of lactation may be brought about by increased intramammary pressure due to non-removal of secretion, as in goats (Peaker, 1980) or to removal of the hormonal galactopoietic stimulus after suckling ceases, as in rats (Hanwell \& Linzell, 1972). RNA $_{t}$ starts to fall within $12 \mathrm{~h}$ of weaning in rats, the fall in DNA (loss of cells) starts 24-36 h later and lasts for up to 20 days (Ota, 1964). A period of involution is an essential pre-requisite for successful redevelopment and subsequent lactation (cows milked continuously until parturition yield considerably less milk than normal in the next lactation (Wheelock \& Dodd, 1969)). This indicates that secretory epithelial cells have a limited life span and must eventually be replaced. Apart from certain above-mentioned exceptions, very little cell division occurs in lactating tissue; hence involution must take place before extensive cell replacement can occur. There is some disagreement as to whether involution completely reverts the gland to its mature, virgin state (as claimed by Tucker \& Reece, 1963) or is incomplete in that some cells are 'carried over' into the next lactation. By labelling mammary epithelial cells of rats with $\left[{ }^{3} \mathrm{H}\right]$ thymidine during one lactation and counting the number of labelled cells during the next lactation, Pitkow, Reece \& Waszilycsak (1972) estimated that carry-over might be as high as $50 \%$. This is likely to be an overestimate, since no correction was made for possible recycling of labelled thymidine from dying cells, but it does suggest that a substantial number of epithelial cells may remain in the gland after involution. Thus mammary development is likely to be incremental in successive gestations, which could explain why milk yield of cattle is more closely related to parity than to age (see Wada \& Turner, 1959).

\section{Control of mammary development}

A number of interacting mechanisms are involved in the control of mammary growth. Development in the fetus is controlled largely by local factors of mesenchymal origin, although the gland rudiments are capable of responding to hormonal stimulation before birth. Development of the duct system during juvenile life is stimulated by mammotrophic hormones of the anterior pituitary, ovaries and adrenals, but local factors are once again important in determining the actual configuration of the growing mammary tree. Mammogenesis during pregnancy is by far the most important developmental phase, and calls for something special in the way of control. It is essential to remember that the ultimate aim is nourishment of the young, thus, although the mammae are part of the maternal body, their size and activity must be appropriate to the needs of the young; thus it is logical to assume that mammogenesis is tailored to meet this requirement. This coupling is achieved in two ways. Firstly, the maternal endocrine mechanisms that stimulate mammogenesis and lactogenesis are also intimately concerned in the maintenance of pregnancy, development of the fetuses and initiation of parturition. Secondly, the developing fetuses are instrumental in producing other strongly mammotrophic hormones (placental lactogens and oestrogens), and thereby directly influence the degree of mammary development. Even after parturition, the mother still does not have complete control over what happens to part of her body, for although the sucking young are no longer capable of having a 
direct endocrine effect on the gland, they do have an indirect one, via their influence on maternal hormone secretion. Also, the degree and frequency of suckling and gland-emptying may affect the way in which local factors within the gland control further development.

Thus control of mammary growth involves a complex hierarchy of interacting mechanisms. There is local control at the level of the gland itself, systemic endocrine control and control by both fetuses in utero and the sucking young post partum. Finally, the influence of environment, diet and the metabolic state of the animal are also crucial to the overall development pattern.

\section{Systemic endocrine control}

We shall be relatively brief in this section, not because the topic is an unimportant one but because we have little in the way of new information to add to a subject that has been extensively reviewed before (see Cowie et al., 1980).

The mammotrophic functions of prolactin, growth hormone, progesterone, oestrogens and corticosteroids were established initially by gland extirpation and hormone replacement experiments in immature rats (Lyons, 1958). The same hormones also promote mammary development in intact, virgin domestic animals (see review by Meites, 1961) and stimulate DNA synthesis and cell proliferation in mammary tissue in vitro (reviewed by Forsyth \& Jones, 1976). The in-vivo experiments have been criticized for failing to demonstrate a direct effect of exogenous hormone(s), which could act indirectly by improving the general condition of endocrinectomized animals or by stimulating release of endogenous hormones in intact animals. Actions demonstrated in vitro must involve direct effects on the tissue, although they do not necessarily also occur in vivo. This may be because cultured tissue differs in certain ways from normal tissue, or because the effect of the hormone, acting permissively, is overridden by other control mechanisms in the intact animal. A classic example of this is insulin, which is essential for mammary growth in vitro but apparently has no specific mammotrophic action in vivo.

Despite these criticisms, these experiments did establish the following points: prolactin and/or growth hormone are essential for normal mammary development in the young animal, and if given in high enough quantities will promote some growth even in the absence of steroids. Together with placental hormones (see later) these are generally referred to as lactogenic hormones. While this description is quite correct (they do have lactogenic properties) it is not a particularly apt title, for they have other roles as well, including stimulation of mammogenesis. If, in addition to prolactin, oestrogens are also present, duct growth (only) will be stimulated, and if progesterone is then added development will proceed to the lobulo-alveolar tissue stage.

By and large these observations agree with what one would expect from actual endocrine patterns. It is difficult to obtain from the literature precise correlations between hormone levels and phases of mammary growth, hence one must look for qualitative rather than quantitative relationships. Hormone concentrations and their relation to mammogenesis have been reviewed by Cowie et al. (1980). In pubertal rats, DNA synthesis, restricted to the ducts, is initiated during the pro-oestrous phase of the cycle (Sutton \& Suhrbier, 1967), shortly after peaks of secretion of oestrogens and prolactin (Butcher, Collins \& Fugo, 1974). Progesterone concentration rises during the luteal phase of the cycle, but by this time prolactin levels have fallen and, since progesterone alone is not an effective stimulus for growth, the gland starts to regress. This pattern is probably fairly typical of most species. The situation changes markedly once conception has occurred. Coitus initiates twice-daily surges of prolactin secretion in rats and mice, and probably other species, and while these continue mammogenesis is stimulated by the combination of prolactin and progesterone. However, prolactin and growth hormone are both secreted in only minimal amounts for the last two thirds of gestation in most species (man is a notable exception). In pseudopregnant animals mammary growth ceases at the time that prolactin secretion falls (Sinha, Wickes \& Baxter, 1978), but in pregnant animals mammary growth is maximal during the later stages of gestation. Concentrations of oestrogens and 
progesterone are generally high at this time, but those hormones are ineffective without a peptide mammotroph of some sort, and in the majority of species, in which prolactin and growth hormone are both low, another hormone must be present.

During early lactation, the pattern of high steroids and low pituitary hormones is essentially reversed. As well as possessing important lactogenic and galactopoietic properties, prolactin may also be crucial post partum as a mammotrophic hormone in the rat and mouse, and possibly in other species.

Showing that the circulating concentration of a particular hormone is high at the time that mammary growth is stimulated is not necessarily evidence of cause and effect. Hormone concentrations can be misleading, partly because the most commonly used technique, radioimmunoassay, measures the immunoreactive properties of the hormone rather than its biological activity, and partly because several factors other than concentration affect the activity of the hormone. Firstly, specific receptor sites must be present on the cell membrane or within the cytosol of the target cells. Receptors for oestrogens, progesterone, corticosteroids, prolactin and growth hormone have been detected in mammary tissue (see Cowie et al., 1980), and it has been shown that their numbers vary with different stages of the reproductive cycle. Prolactin is bound relatively poorly by pregnant rat mammary tissue but well by lactating tissue (Hayden, Bonney \& Forsyth, 1979a); progesterone receptors on the other hand are present in pregnant, but not lactating mouse tissue (Haslam \& Shyamala, 1979), although they are found in lactating goat tissue (Markland \& Hutchens, 1977). Since receptor levels are themselves under endocrine control, positive and negative feedback loops may be set up. Oestrogen receptors are generally oestrogen independent, are induced by prolactin and are inhibited by progesterone. Oestrogens increase the binding of both progesterone and prolactin, and self-regulation of prolactin receptors by prolactin has also been demonstrated.

This introduces a very important aspect of endocrine control, namely the interactions that occur between different hormones. The importance of the combination of peptide and steroid hormones has already been stressed; a more specific example is found in the action of oestrogens, which not only stimulate the release of prolactin from the pituitary (Meites et al., 1972) but also have a localized effect on mammary tissue, sensitizing it to the action of prolactin possibly by inducing prolactin receptors (Nagasawa \& Yanai, 1971a).

Hormone action at the intracellular level is still only poorly understood, and is obviously an important area for future research. Two other hormones, thyroxine and relaxin, have been implicated in the control of mammary growth. Mammary growth is inhibited and accelerated in young hypo- and hyper-thyroid rats respectively (Vonderhaar \& Greco, 1979). This is most probably a result of the action of thyroxine on general metabolism, rather than a direct effect on the gland. Relaxin synergizes with pituitary and ovarian hormones to stimulate growth in young ovariectomized-hypophysectomized rats (Harness \& Anderson, 1977) but inhibits steroidinduced mammary development in virgin goats (Cowie et al., 1965), hence its role may vary from species to species.

\section{Feto-maternal interactions in the control of mammogenesis}

As indicated above, the pituitary secretes only minimal amounts of prolactin and growth hormone for much of gestation in many species, yet mammary growth is generally maximal at this time. There is now considerable evidence to show that the placenta 'takes over' at this time as the prime source of mammotrophic hormones, secreting considerable amount of a peptide hormone similar to prolactin, and called placental lactogen. The relative unimportance of the pituitary can be shown by hypophysectomizing pregnant animals. In those species in which pregnancy is maintained, mammogenesis is either totally unaffected (e.g. rat: Anderson, 1975a) or only partly inhibited (e.g. goats: Buttle, Cowie, Jones \& Turvey, 1979; sheep: Denamur \& Martinet, 1961). Ovariectomy or fetectomy of pregnant rats and mice has no significant effect 
on mammogenesis, either, provided that the placentae remain intact; if the placentae are removed then mammogenesis ceases (Desjardins, Paape \& Tucker, 1968). Placental extracts also stimulate mammary growth in hypophysectomized, ovariectomized virgin rats when given together with steroids (Ray, Averill, Lyons \& Johnstone, 1955), and, in vitro, growth of mammary explants is promoted by co-culture with placental fragments (Forsyth \& Jones, 1976).

Placental lactogen concentrations have been measured in some species using specific radioimmunoassays, and total lactogenic activity (i.e. placental lactogen plus prolactin) has been measured by radioreceptor assay or bioassay in others. For technical reasons it is not entirely valid to subtract immunoreactive prolactin from total lactogenic activity to obtain values for placental lactogen, although in those species in which very little prolactin is secreted during pregnancy, total lactogenic activity may be equated to placental lactogen. Generally speaking, placental lactogen cannot be detected during the first third of gestation, but from then on its concentration rises and is maintained at a high level until just before parturition (Kelly, Tsushima, Shiu \& Friesen, 1976). Placental lactogen secretion has recently been reviewed by Cowie et al. (1980).

Is mammary growth correlated with placental lactogen secretion? As far as timing is concerned, the general pattern is correct, since both are maximal during the last two-thirds of gestation. Mammary growth is initiated between Days 4 and 6 of pregnancy in rats and mice, and cell proliferation is at its highest on Day 12. The earliest that rat placental lactogen has been detected is Day 6 (Kohmoto \& Bern, 1970), and the peak values reported by Kelly et al. (1976) occur at mid-pregnancy, i.e. around Day 12 . Is mammary growth related to the concentration of placental lactogen? We are not aware of any data pertaining specifically to this point. The closest anybody has got to this is in the goat, for which Hayden, Thomas \& Forsyth (1979b) demonstrated a positive correlation between mean placental lactogen concentration during the second half of gestation and milk yield in the succeeding lactation. The hormone concentration was also related to the number of fetuses carried, which was in turn related to the weight of the trimmed udder (largely lobulo-alveolar tissue) at the end of gestation. This is strongly indicative of an effect of placental lactogen concentration on mammary growth in this species. As with other hormones, several factors other than concentration may be important in regulating the action of placental lactogen. The same lactogenic hormone receptors that bind prolactin also bind placental lactogen, therefore the number of these receptors will be important, as will the affinity of placental lactogen for the receptor and the amount of competitive binding by non-biologically active compounds.

We suggested in the introduction to this section that fetal control of mammogenesis would be a desirable trait, and in placental lactogen we potentially have a mechanism whereby this could be achieved. Let us consider, from a theoretical point of view, the likelihood of demonstrating such an effect in different species. Firstly, it is not likely to be apparent in species which secrete large amounts of pituitary mammotrophic hormones (prolactin and growth hormone) throughout pregnancy, since the importance of placental lactogen would no longer be absolute. The only known species of this type is man; paradoxically, human placental lactogen is one of the best known placental lactogens and is highly active. Some species apparently produce little or no placental lactogen. Co-culture experiments have failed to detect lactogenic activity in the placentae of pigs and horses, and there are question marks for the dog and the rabbit. More information is needed before we can be sure of the source of peptide mammotrophic hormones in these species; if placental lactogen is indeed not present then the fetuses will be unable to influence mammogenesis in this fashion, although feto-placental oestrogen production must also be considered.

The fetal influence should be more marked in species which do not exhibit lactational mammary growth, since there is then no possibility of correction for inappropriate gestational development. It is less likely to be observed in species which give birth to immature young (e.g. marsupials) than in those with a long gestation period which bear mature young. The guinea-pig 
is a prime example of the latter type, but in this case the extreme maturity of the young at birth means that they are frequently able to take solid food immediately, which could be related to a lack of fetal control over mammary development.

So much for theory; what evidence do we have that the fetuses are able to influence mammogenesis in any species? Correlations have been demonstrated between fetal number and gland development in goats, as mentioned above. Polytocous sheep possess heavier glands at the end of gestation than monotocous ones (Rattray, Garrett, East \& Hinman, 1974), an effect which may be mediated through placental lactogen since other experiments have shown that the hormone concentration is related to the number of fetuses carried (Taylor et al., 1980). Placental lactogen secretion is unlikely to be simply a function of placental mass (and hence fetal number) in all species. Experiments in mice have demonstrated that fetal number and mammary growth are correlated up to a maximum of 8 feto-placental units; thereafter either placental lactogen secretion is not enhanced or the gland is unable to respond further to the hormone (Nagasawa \& Yanai, 1971b). Rats need a minimum of only 3 feto-placental units to ensure maximum mammary development (Anderson, 1975a), and prolactin secretion may be enhanced in pregnant rats by self-licking of nipples, a phenomenon which is apparently necessary for normal mammogenesis, since if it is prevented mammary growth is reduced (Roth \& Rosenblatt, 1968). In guinea-pigs, mammary gland weight and milk yield at peak lactation are both correlated with the number of young born, rather than the number suckled (Davis, Mepham \& Lock, 1979), which is once again indicative of a fetal effect on mammogenesis.

In conclusion, it is well established that a peptide mammotrophic hormone is essential for normal mammogenesis in all species. In many it would appear that placental lactogen is quantitatively of greater importance than prolactin, and because placental lactogen secretion may be related to fetal number and mass, so the fetuses may exert considerable control over mammogenesis.

\section{The influence of the sucking young on mammary development}

In this section we shall consider the influence of the suckling stimulus on early lactational growth, mainly in the rat and mouse. Later in lactation the intensity of suckling may also affect preparation for the next lactation in concurrently pregnant and lactating animals, but this normally involves delaying or extending gestation rather than directly affecting mammogenesis.

There is a close correlation between the DNA content of rat mammary glands at peak lactation and the number of young suckled (Tucker, 1966). The maximum young:gland ratio used was 1, hence we do not know that the amount of growth achieved (total DNA doubled between Days 1 and 16 of lactation) was actually the maximum possible. Also, it should be remembered that the differences in DNA content between groups with high and low suckling intensities were due in part to stimulation of growth in the former and in part to regression in the latter, which complicates any relationship between fetal number and lactational growth per se.

Our own results for mice show that post-parturient growth can indeed be stimulated by an increased number of young, but that this effect is limited to the first few days of lactation. Mammary cell proliferation peaks at $48 \mathrm{~h}$ post partum and is essentially over by the 5 th day of lactation in mice (C. H. Knight \& M. Peaker, unpublished). We now have evidence to show that when gestational growth is decreased by reducing the number of fetuses carried experimentally, the animal will compensate by increasing the amount of growth occurring in early lactation if it is given extra young to suckle (young:gland ratio of 0.9 ), but will not if it only suckles its own, reduced-size litter (young: gland ratio of $0.4-0.5$ ). We should like to suggest that those species that exhibit marked lactational mammary growth may be those which live a communal existence and which are known to cross-suckle readily, so that the number of young suckled may be greater than the number of fetuses carried. In other words, the lactational growth spurt may be a 'catch-up' mechanism for ensuring that yield is truly proportional to demand. 
The rat results (Tucker, 1966) reflect a rather different situation. For a start, the litter size was adjusted down, rather than up, and this adjustment was made on Day 3 of lactation, which may be after the main burst of cell proliferation. The growth response was a long-term one, lasting for almost 2 weeks, rather than the short affair observed in the mouse. It is logical to assume that suckling-induced growth is due to increased release of prolactin, which was unfortunately not measured in the rat study, although the results do not support this hypothesis. The young:gland ratio seemed to be the important factor, rather than the overall suckling stimulus. The 6 glands of rats suckling 6 young, with the remaining glands teat-sealed to prevent sucking, contained just as much DNA as the equivalent 6 glands of rats suckling 12 young to 12 glands. Hence it may be that local factors, possibly involving the degree of milk removal, are just as important as the systemic mammotrophic stimulus.

\section{Local control of mammary development}

Morphogenesis of the fetal mammary rudiment is controlled by a diffusible chemical factor(s) of mesenchymal origin (Kratochwil, 1969). If the normal mammary mesenchyma is replaced by salivary gland mesenchyma, the mammary epithelium will develop a salivary gland-like appearance, although this does not prevent it from differentiating and producing specific milk products if given the correct stimulus. Hence the effect of the mesenchymal factor is purely on morphogenesis; cytodifferentiation appears to be controlled by factors intrinsic to the epithelium. Mesenchymal-factor activity is reduced by collagenase, which is interesting in view of the fact that mature virgin mammary tissue shows a specific collagen requirement for extended growth in vitro (Wicha, Liotta, Garbisa \& Kidwell, 1979). Mammary tissue only develops in vivo in white-fat pads, possibly because of the presence in white fat of a substance(s) similar to or identical with the mesenchymal factor, which may be collagen. Whether the factor(s) present in the mesenchyma and fat pad are directly mitogenic or merely permissive agents is not known. Various growth factors are known to stimulate mammary cell proliferation in vitro, although as yet no specific role in vivo has been suggested. Klagsbrun (1978) and Swanson \& Moore (1979) have identified two apparently different factors in milk and mammary tissue respectively, both of which are mitogenic and are produced by the mammary gland itself. Their physiological significance still requires elucidation.

As well as these stimulatory factors there are also a number of locally acting inhibitory factors in the mammary gland. During morphogenesis, development of the duct system is not haphazard but conforms to a definite form and shape. Adjacent ducts never approach closer than $0.25 \mathrm{~mm}$ to each other, thus allowing space for subsequent development of alveoli. Faulkin \& De Ome (1960) have shown that normal and pre-neoplastic mammary duct tissue produces a chemical of some sort which diffuses into the adjacent fat pad and prevents other ducts from penetrating into that area (although their growth as such is not inhibited, because they may turn away and continue proliferating in other directions). One of the abnormalities of neoplastic tissue is a failure to respond to this inhibitory influence. The factor is completely local in its action, and is not produced in sufficient quantities to have a systemic effect; e.g. if one or more developing mammary duct systems are removed from young mice the growth of the remaining glands is not increased to compensate (Nicoll, 1965).

The question of compensatory growth has been studied in guinea-pigs and goats, as well as in mice. Kuosaite (1965) claimed to have demonstrated compensation of the single remaining gland of hemimastectomized guinea-pigs during gestation, although we have been unable to repeat this result (Knight \& Peaker, 1982a). W de, however, have preliminary evidence for compensation of the single gland of hemimastectomized lactating goats, both in terms of yield and gross size (C. H. Knight \& M. Peaker, unpublished results). Compensatory growth has been demonstrated in a number of other tissues, notably kidney and liver, and may be prevented by giving repeated injections of extracts of the same tissue. It has therefore been suggested that 
some tissues control their own growth rate by producing locally acting chemical inhibitors of cell proliferation and/or DNA synthesis (chalones: see review by Bullough, 1973), whose local and, in the case of large tissues, systemic, concentration is reduced following removal of part of that tissue mass, so that growth of the remainder is stimulated. Is it possible that the mammary gland produces a mammary chalone?

Gonzalez \& Verly (1976) have isolated and partly purified from mammary gland a compound of molecular weight 2000-3000 which specifically and reversibly inhibits DNA synthesis in mammary tissue. Lehmann, Graetz, Samtleben, Schutt \& Langren (1980) have identified a similar compound in cells of the Ehrlich ascites mammary carcinoma, and our own investigations (unpublished) have also suggested the existence of such a compound. What is the significance of such a finding? It is almost impossible to believe that the fine degree of growth control exerted over the mammary gland could be achieved by stimulatory compounds alone. Faulkin \& De Ome (1960) suggested that control consisted of systemic humoral stimulation countered by local inhibition. It is too early to claim that the inhibitory compound they identified in juvenile tissue was a mammary chalone, although this is quite possible. Once the chalone is readily available we would wish to test its effects on mammary growth in vivo, and also to measure its endogenous concentration at different stages of the reproductive cycle. A low concentration would be expected during gestation, when the growth rate is high. So far, no explanation has been presented for the inhibition of mammary growth during lactation. We have shown that mouse mammary tissue is incapable of responding to exogenous hormonal stimulation at peak lactation, but recovers this ability later in lactation. Franke \& Keenan (1979) have shown that differentiated mammary epithelial cells are still capable of dividing, hence they must be prevented from doing so in some way, and the mammary chalone may be responsible for this. The lack of compensatory growth following partial mastectomy of mice and guinea-pigs suggests that the effect of the mammary chalone is purely a local one, although the same may not be true of goats. Also, if the lactating gland produces large amounts of chalone it may be secreted into the milk in sufficiently large quantities to affect the development of the mammary gland of the sucking young, a mechanism that was proposed many years ago when it was suggested that growth might be suppressed in young, sucking rats, rather than stimulated by prepubertal hormone release following weaning (Cowie, 1949).

\section{Effects of nutrition on mammary development}

Both undernutrition and overnutrition are capable of impairing mammary development. Heifers fed a high carbohydrate diet from 4 weeks of age develop fatty glands with less lobulo-alveolar tissue than normally fed controls, and this is reflected in their decreased milk yield (I. W. Reynolds, personal communication). Rats fed $70 \%$ of their normal consumption from weaning had smaller glands than controls at the end of their first pregnancy, but this may have been due to an increased fat content in the group fed ad libitum, since the restricted group apparently lactated better and there was no difference between the groups in terms of mammary weight at the end of lactation (Sykes, Wrenn \& Hall, 1948). Hormone-stimulated mammary growth is inhibited by a $50 \%$ reduction in food intake (Srivastava \& Turner, 1966), and protein deficiencies in the diet also lead to reduced mammary growth in virgin and pregnant rats (Pyska \& Styczynski, 1979).

Whether inappropriate nutrition acts directly on the gland or indirectly via an effect on general metabolism or on the production of specific hormones is not known, although the latter explanation is favoured since it is known that malnutrition affects the secretion of prolactin, growth hormone and thyroid hormones. We have studied the effect of short periods of starvation at mid-pregnancy or immediately post partum on mammary growth in mice. Starvation during pregnancy reduces mammary weight and DNA content at the end of the pregnancy, but the gland apparently recovers during early lactation since the growth rate of the litter is normal. 
Starvation on Day 1 of lactation has a severe inhibitory effect on the incorporation of $\left[{ }^{3} \mathrm{H}\right]$ thymidine into DNA measured on Day 2 , although once again the gland subsequently recovers from this temporary setback.

The fact that these effects occur demonstrate that the gland is not immune to external influences. However, even severe treatments, such as starvation of pregnant mice for $40 \mathrm{~h}$, have only a temporary inhibitory effect on development in this species; thus it would appear that the mother attempts to maintain normal mammary development, and thereby sustain her young, almost at any cost.

\section{Mammary control of reproduction}

The first part of this article is an example of the way in which the mammary gland has been viewed by the endocrinologist - as a receiver but not as a sender (except by way of the milk-ejection reflex during lactation) of signals. This view must now be modified in view of the results of experiments which show that if goats are mastectomized when young there are marked disturbances in the oestrous cycle (Peaker \& Maule Walker, 1981), effects on fertility, and progressively more severe disturbances during late pregnancy and at parturition (Maule Walker \& Peaker, 1981). It would appear that, at least in this species, the mammary gland has an endocrine role in the integration of reproductive events, but whether we are dealing with known hormones (e.g. production of oestradiol-17 $\beta$ in late pregnancy: Maule Walker \& Peaker, 1978) or unknown factors is open to speculation.

While these observations appear to be new, older anecdotal evidence indicates the importance of the mammary gland for normal reproduction. For example, Marshall \& Kirkness (1907), working in the University of Edinburgh, mastectomized guinea-pigs to investigate the source of the lactose in milk. They noted "considerable difficulty was experienced in inducing the guinea-pigs to breed after the removal of the glands, some of them failing to do so although kept for over eight months in company with males, and in an apparently perfectly healthy condition".

Only now are we beginning to exploit this forgotten finding of F. H. A. Marshall, the doyen of reproductive physiology commemorated by the Society for the Study of Fertility, in opening up a fascinating and fertile field of mammary physiology.

\section{References}

Anderson, R.R. (1975a) Mammary gland growth in the hypophysectomised pregnant rat. Proc. Soc. exp. Biol. Med. 148, 283-287.

Anderson, R.R. (1975b) Mammary gland growth in sheep. J. Anim. Sci. 41, 118-123.

Anderson, R.R., Harness, J.R., Snead, A.F. \& Salah, M.S. (1981) Mammary growth pattern in goats during pregnancy and lactation. J. Dairy Sci. 64, $427-432$.

Baldwin, R.L. (1966) Enzymatic activities in mammary glands of several species. J. Dairy Sci. 49, 15331542.

Balinsky, B.I. (1950) On the prenatal growth of the mammary gland rudiment in the mouse. J. Anat. 84, 227-235.

Bresciani, F. (1971) Ovarian steroid control of cell proliferation in the mammary gland and cancer. In Basic Actions of Sex Steroids on Target Organs, pp. 130-159. Eds P. O. Hubinont, F. Leroy \& P. Galand. Karger, Basel.
Brookreson, A.D. \& Turner, C.W. (1959) Normal growth of mammary gland in pregnant and lactating mice. Proc. Soc. exp. Biol. Med. 102, 744-745.

Bullough, W.S. (1973) The chalones: a review. Natn Cancer Inst. Monogr. 38, 5-16.

Butcher, R.L., Collins, W.E. \& Fugo, N.W. (1974) Plasma concentration of LH, FSH, prolactin, progesterone and estradiol-17 $\beta$ throughout the 4-day estrous cycle of the rat. Endocrinology 94, 17041708.

Buttle, H.L., Cowie, A.T., Jones, E.A. \& Turvey, A. (1979) Mammary growth during pregnancy in hypophysectomised or bromocriptine-treated goats. J. Endocr. 18, 343-351.

Cowie, A.T. (1949) The relative growth of the mammary gland in normal, gonadectomized and adrenalectomized rats. J. Endocr. 6, 146-157.

Cowie, A.T., Cox, C.P., Folley, S.J., Hoskins, Z.D., Naito, M. \& Tindal, J.S. (1965) The effects of the duration of treatments with oestrogen and pro- 
gesterone on the hormonal induction of mammary growth and lactation in the goat. $J$. Endocr. 32, $129-139$.

Cowie, A.T., Forsyth, I.A. \& Hart, I.C. (1980) Hor monal Control of Lactation. Springer-Verlag, Berlin.

Davis, S.R., Mepham, T.B. \& Lock, K.J. (1979) Relative importance of prepartum and postpartum factors in the control of milk yield in the guinea-pig. J. Dairy Res. 46, 613-621.

Denamur, R. \& Martinet, J. (1961) Effects de l'hypophysectomie et de la section de la tige pituitaire sur la gestation de la brebis. Annls Endocr. 22, 755-759.

Desjardins, C., Paape, M.J. \& Tucker, H.A. (1968) Contribution of pregnancy, fetuses, fetal placentas and deciduomas to mammary gland and uterine development. Endocrinology 83, 907-910.

Devore, G. (1977) Ultrastructural evidence for differentiation of mammary gland secretory cells from a population of primitive cells basally located in the epithelium. J. Cell Biol. 75, 33a.

Dossett, J.A. (1960) The nature of breast secretion in infancy. J. Path. Bact. 80, 93-99.

Faulkin, L.J. \& De Ome, K.B. (1960) Regulation of growth and spacing of gland elements in the mammary fat pad of the $\mathrm{C} 3 \mathrm{H}$ mouse. J. natn. Cancer Inst. 24, 953-969.

Fleet, I.R., Goode, J.A., Hamon, M.H., Laurie, M.S., Linzell, J.L. \& Peaker, M. (1975) Secretory activity of goat mammary glands during pregnancy and the onset of lactation. J. Physiol., Lond. 251, 763773.

Forsyth, I.A. \& Jones, E.A. (1976) Organ culture of mammary gland and placenta in the study of hormone action and placental lactogen secretion. In Organ Culture in Biomedical Research, pp. 201221. Eds M. Balls \& M. A. Monnickendam. Cambridge University Press.

Foster, R.C. (1977) Changes in mouse mammary epithelial cell size during mammary gland development. Cell Diff. 6, 1-8.

Franke, W.W. \& Keenan, T.W. (1979) Mitosis in milk secreting epithelial cells of mammary gland. An ultrastructural study. Differentiation 13, 81-88.

Gonzalez, R. \& Verly, W.G. (1976) Isolation of an inhibitor of DNA synthesis specific for normal and malignant mammary cells. Proc. natn. Acad. Sci. U.S.A. 73, 2196-2200.

Grahame, R.E. \& Bertalanffy, F.D. (1972) Cell division in normal and neoplastic mammary gland tissue in the rat. Anat. Rec. 174, 1-7.

Greenbaum, A.L. \& Slater, T.F. (1957) Studies on the particulate components of rat mammary gland. (ii) Changes in the levels of the nucleic acids of the mammary glands of rats during pregnancy, lactation and mammary involution. Biochem. J. 66, 155-161.

Griffith, D.R. \& Turner, C.W. (1961) Normal growth of rat mammary glands during pregnancy and early lactation. Proc. Soc. exp. Biol. Med. 106, 448-450.

Hanwell, A. \& Linzell, J.L. (1972) A simple technique for measuring the rate of milk secretion in the rat. Comp. Biochem. Physiol. 43A, 250-270.

Harness, J.R. \& Anderson, R.R. (1977) Effect of relaxin and somatotrophin in combination with ovarian steroids on mammary glands in rats. Biol. Reprod. 17, 599-603.
Haslam, S.Z. \& Shyamala, G. (1979) Progesterone receptors in normal mammary glands of mice: characterization and relationship to stage of development. Endocrinology 105, 786-795.

Hayden, T.J., Bonney, R.C. \& Forsyth, I.A. (1979a) Ontogeny and control of prolactin receptors in the mammary gland and liver of virgin, pregnant and lactating rats. J. Endocr. 80, 259-269.

Hayden, T.J., Thomas, C.R. \& Forsyth, I.A. (1979b) Effect of number of young born (litter size) on milk yield of goats: role for placental lactogen. J. Dairy Sci. 62, 53-57.

Keenan, T.W., Saacke, R.G. \& Patton, S. (1970) Prolactin, the golgi apparatus and milk secretion. Brief interpretative review. J. Dairy Sci. 53, 13491352.

Kelly, P.A., Tsushima, T., Shiu, R.P.C. \& Friesen, H.G. (1976) Lactogenic and growth-hormone like activities in pregnancy determined by radioreceptor assays. Endocrinology 99, 765-774.

Klagsbrun, M. (1978) Human milk stimulates DNA synthesis and cellular proliferation in cultured fibroblasts. Proc. natn. Acad. Sci. U.S.A. 75, 50575061.

Knight, C.H. \& Peaker, M. (1982a) Lack of compensatory mammary growth following hemimastectomy in the guinea-pig. Comp. Biochem. Physiol. 704, 427-429.

Knight, C.H. \& Peaker, M. (1982) Mammary cell proliferation in mice during pregnancy and lactation in relation to milk yield. $Q$. $J l$ exp. Physiol. 67, 165-177.

Kohmoto, K. \& Bern, H.A. (1970) Demonstration of mammotrophic activity of the mouse placenta in organ culture and by transplantation. J. Endocr. 48, 99-107.

Korfsmeier, K.-H. (1979) Proliferation kinetics in the mammary gland of the mouse during postnatal development. Anat. Anz. 145, 313-318.

Kratochwil, K. (1969) Organ specificity in mesenchymal induction demonstrated in the embryonic development of the mammary gland of the mouse. Devl Biol. 20, 46-71.

Kuosaite, B.A. (1965) Compensatory hypertrophy of the mammary gland in the guinea-pig following the removal of the right mammary gland. Bull. exp. Biol. Med. U.S.S.R. 59, 317-320.

Lehmann, W., Graetz, H., Samtleben, R., Schutt, M. \& Langren, P. (1980) On a 'chalone' like factor for the Ehrlich ascites mammary carcinoma. Acta biol. med. germ. 39, 93-105.

Linzell, J.L. (1966) Measurement of udder volume in live goats as an index of mammary growth and function. J. Dairy Sci. 49, 307-311.

Lu, M.H. \& Anderson, R.R. (1973) Growth of the mammary gland during pregnancy and lactation in the rabbit. Biol. Reprod. 9, 538-543.

Lyons, W.R. (1958) Hormonal synergism in mammary growth. Proc. $R$. Soc. $B$ 149, 303-325.

Markland, F.S. \& Hutchens, T.W. (1977) Characterization of the progestin receptor from lactating mammary glands of the goat. Prog. Cancer Res. Ther. 4, 23-38.

Marshall, F.H.A. \& Kirkness, J.M. (1907) On the formation of lactose. Biochem. J. 2, 1-6. 
Marshall, W.A. \& Tanner, J.M. (1969) Variations in pattern of pubertal changes in girls. Archs Dis. Childh. 44, 291-303.

Maule Walker, F.M. \& Peaker, M. (1978) Production of oestradiol-17 $\beta$ by the goat mammary gland during late pregnancy in relation to lactogenesis. J. Physiol., Lond. 284, 71-72P.

Maule Walker, F.M. \& Peaker, M. (1981) The role of the mammary gland in late pregnancy and parturition in the goat. J. Physiol., Lond. 312, 63P.

Mayer, G. \& Klein, M. (1961) Histology and cytology of the mammary gland. In Milk: the Mammary Gland and its Secretion, vol. 1, pp, 47-126. Eds S. K. Kon \& A. T. Cowie. Academic Press, New York.

Meites, J. (1961) Farm animals: hormonal induction of lactation and galactopoiesis. In Milk: the Mammary Gland and its Secretion, vol. 1, pp. 321-367. Eds S. K. Kon \& A. T. Cowie. Academic Press, New York.

Meites, J., Lu, K.H., Wuttke, W., Welsch, C.W., Nagasawa, H. \& Quadri, S.K. (1972) Recent studies on functions and control of prolactin secretion in rats. Recent Prog. Horm. Res. 28, 471-526.

Munford, R.E. (1963) Changes in the mammary glands of rats and mice during pregnancy, lactation and involution. (ii) Levels of deoxyribonucleic acid, and alkaline and acid phosphatases. J. Endocr. 28, 17-34.

Munford, R.E. (1964) A review of anatomical and biochemical changes in the mammary gland with particular reference to quantitative methods of assessing mammary development. Dairy Sci. Abstr. 26, 293-304.

Nagasawa, H. \& Yanai, R. (1971a) Increased mammary gland response to pituitary mammotrophic hormones by estrogen in rats. Endocr. jap. 18, 53-56.

Nagasawa, H. \& Yanai, R. (1971b) Quantitative participation of placental mammotrophic hormones in mammary development during pregnancy of mice. Endocr.jap. 18, 507-510.

Nagasawa, H. \& Yanai, R. (1976) Mammary nucleic acids and pituitary prolactin secretion during prolonged lactation in mice. J. Endocr. 70, 389-395.

Nelson, W.L., Heytler, P.G. \& Ciaccio, E.I. (1962) Guinea-pig mammary gland growth changes in weight, nitrogen and nucleic acids. Proc. Soc. exp. Biol. Med. 109, 373-375.

Nicoll, C.S. (1965) Growth autoregulation and the mammary gland. J. natn. Cancer Inst. 34, 131-140.

Ota, K. (1964) Mammary involution and engorgement after arrest of suckling in lactating rats indicated by the contents of nucleic acids and milk protein of the gland. Endocr.jap. 11, 146-152.

Paape, M.J. \& Sinha, Y.N. (1971) Nucleic acid and collagen content of mammary glands between 30 and 80 days of age in normal and ovariectomized rats and during pregnancy. J. Dairy Sci. 54, 1068-1074.

Peaker, M. (1980) The effect of raised intramammary pressure on mammary function in the goat in relation to the cessation of lactation. J. Physiol., Lond. 301, $415-428$.

Peaker, M. \& Maule Walker, F.M. (1981) Mastectomy and mammary glands in reproductive control in the goat. Nature, Lond. 284, 165-166.

Pitkow, H.S., Reece, R.P. \& Waszilycsak, G.L. (1972) The integrity of mammary alveolar cells in two consecutive lactations. Proc. Soc. exp. Biol. Med. 139, 845-850.

Pyska, H. \& Styczynski, H. (1979) Effect of various protein levels in the diet on mammary gland growth in rats. J. Dairy Res. 46, 551-554.

Rattray, P.V., Garrett, W.N., East, N.E. \& Hinman, N. (1974) Growth, development and composition of the ovine conceptus and mammary gland during pregnancy. J. Anim. Sci. 38, 613-626.

Ray, E.W., Averill, S.C., Lyons, W.R. \& Johnstone, R.E. (1955) Rat placental hormonal activities corresponding to those of pituitary mammotrophin. Endocrinology 56, 359-373.

Roth, L.L. \& Rosenblatt, J.S. (1968) Self-licking and mammary development during pregnancy in the rat. J. Endocr. 42, 363-378.

Short, R.V. \& Drife, J.O. (1977) The aetiology of mammary cancer in man and animals. In Comparative Aspects of Lactation, pp. 211-230. Ed. M. Peaker. Academic Press, London.

Sinha, Y.N. \& Tucker, H.A. (1966) Mammary gland growth of rats between 10 and 100 days of age. $\mathrm{Am}$. J. Physiol. 210, 601-605.

Sinha, Y.N. \& Tucker, H.A. (1969) Mammary development and pituitary prolactin level of heifers from birth through puberty and during the estrous cycle. $J$. Dairy Sci. 52, 507-512.

Sinha, Y.N., Anderson, R.R. \& Turner, C.W. (1970) Growth of the mammary glands of the golden hamster, Mesocricetus auratus. Biol. Reprod. 2, 185-188.

Sinha, Y.N., Wickes, M.A. \& Baxter, S.R. (1978) Prolactin and growth hormone secretion and mammary gland growth during pseudopregnancy in mouse. J. Endocr. 77, 203-221.

Srivastava, L.S. \& Turner, C.W. (1966) Restricted feed growth. J. Dairy Sci. 49, 1050-1052.

Sutton, H. \& Suhrbier, K. (1967) The estrous cycle and DNA synthesis in the mammary gland. Argonne natn. Lab. U.S. Atomic Energy Commn Annual Rep. $157-158$.

Swanson, T.L. \& Moore, G.E. (1979) Bovine mammary gland contains a growth promoter for human breast cancer cell lines: colo. 378 and colo. 384. Biochem. biophys. Res. Commun. 90, 1166-1171.

Sykes, J.F., Wrenn, T.R. \& Hall, S.R. (1948) The effect of inanition on mammary gland development and lactation. J. Nutr. 35, 467-476.

Taylor, M.J., Jenkin, G., Robinson, J.S., Thorburn, G.D., Friesen, H. \& Chan, J.S.D. (1980) Concentrations of placental lactogen in chronically catheterized ewes and fetuses in late pregnancy. $J$. Endocr. 85, 2734.

Traurig, H.H. (1967a) Cell proliferation in the mammary gland during late pregnancy and lactation. Anat. Rec. 157, 489-503.

Traurig, H.H. (1967b) A radioautographic study of cell proliferation in the mammary gland of the pregnant mouse. Anat. Rec. 159, 239-244.

Tucker, H.A. (1966) Regulation of mammary nucleic acid content by various suckling intensities. $A m$. J. Physiol. 210, 1209-1214.

Tucker, H.A. \& Reece, R.P. (1963) Nucleic acid content of rat mammary glands during post-lactational 
involution. Proc. Soc. exp. Biol. Med. 112, 10021004.

Vonderhaar, B.K. Greco, A.E. (1979) Lobulo-alveolar development of mouse mammary glands is regulated by thyroid hormones. Endocrinology 104, 409-418.

Wachter, H., Hausen, A., Reider, E. \& Schweiger, M. (1980) Pteridine excretion from cells as indicator of cell proliferation. Naturwissenschaften 67, 610-612.

Wada, H. \& Turner, C.W. (1959) Effect of recurring pregnancy on mammary gland growth in mice. $J$. Dairy Sci. 42, 1198-1202.

Wheelock, J.V. \& Dodd, F.H. (1969) Non-nutritional factors affecting milk yield in dairy cattle. J. Dairy Res. 36, 479-493.

Wicha, M.S., Liotta, L.A., Garbisa, S. \& Kldwell, W.R. (1979) Basement membrane collagen requirements for attachment and growth of mammary epithelium Expl Cell Res. 124, 181-190. 